\title{
Kinerja di Era 4.0: Apakah Teknologi Informasi dan Knowledge Sharing itu Penting?
}

\author{
${ }^{1}$ I Nengah Aristana, ${ }^{2}$ Ni Komang Tri Rahayu Dewi \\ Universitas Triatma Mulya, Bali, Indonesia \\ Email : nengah.aristana@triatmamulya.ac.id
}

(Diterima: September 2021; Direvisi: Oktober 2021; Dipublikasikan: Januari 2022)

\begin{abstract}
ABSTRAK
Penelitian ini bertujuan untuk menganalisis pengaruh teknologi informasi dan knowledge sharing terhadap kinerja pegawai. Penelitian ini dilakukan pada Dinas Kebudayaan Kabupaten Karangasem, dimana pengumpulan data menggunakan kuesioner. Populasi penelitian ini adalah seluruh pegawai yang bekerja pada Dinas Kebudayaan Kabupaten Karangasem yang berjumlah 49 orang, sehingga metode penentuan sampel menggunakan metode sampel jenuh. Sedangkan untuk teknik analisis data penelitian ini menggunakan analisis jalur (path analysis) dengan SPSS 21. Hasil penelitian ini menunjukkan bahwa teknologi informasi berpengaruh signifikan terhadap knowledge sharing, namun berpengaruh tidak signifikan mempengaruhi kinerja pegawai, knowledge sharing berpengaruh signifikan terhadap kinerja pegawai dan knowledge sharing berperan sebagai pemediasi penuh pengaruh teknologi informasi terhadap kinerja pegawai.
\end{abstract}

Kata Kunci: Teknologi Informasi, Knowledge Sharing dan Kinerja Pegawai 


\section{PENDAHULUAN}

Perkembangan era informasi 4.0 dan adanya reformasi disegala sector menjadikan organisasi harus melakukan perbaikan dalam pengelolaan organisasi (Anderson, 2010). Saat ini pengabdopsian teknologi informasi menjadi satu hal yang harus dilakukan untuk meningkatkan efektivitas organisasi dalam mencapai tujuan yang telah ditetapkan (Lee et al., 2014; GarcíaSánchez et al., 2018). Maskudi (2014) menyebutkan pengadopsian teknologi informasi secara garis besarnya dapat membantu penyelesaian beban pekerjaan yang dimiliki karyawan. Selain itu, penerapan teknologi yang dilakukan secara berkesinambungan menjadi pendorong utama karyawan keluar dari tekanan kegiatan (ElKassar \& Singh, 2019). Pengadopsian teknologi eksternal bermanfaat untuk meningkatkan kinerja inovatif dan ini memberikan efek yang lebih kuat dalam menghadapi perubahan lingkungan (Lee et al., 2017; GarcíaSánchez et al., 2018). Melalui teknologi informasi dalam bentuk perlatan teknis yang memiliki fungsi sebagai mengolah dan mendistribusikan informasi.

Seperti halnya organisasi lainya, organisasi sektor publik saat ini juga melakukan restrukturisasi terhadap organisasi dengan mengadopsi teknologi untuk mendapatkan manfaat melalui pengurangan hambatan yang nantinya memberikan dampak pada kinerja $(\mathrm{H}$. Y. Hsu et al., 2019), hal ini dikarenakan operasionalisasi teknologi bergantung pada peran karyawan (Maskudi, 2014). Melalui penerapan teknologi diharapkan dapat meningkatkan pelayanan sehingga hasil yang dicapai lebih efektif dan efisien (Bonacina Roldan et al., 2018). Lee et al. (2017) menjelaskan keberhasilan organisasi untuk menggunakan teknologi sangat ditentukan oleh faktor kemampuan lingkungan internal. Penyedian teknologi yang dibutuhkan dapat mengatur dan menghasilkan ide dalam lingkungan kolaboratif, menentukan prioritas dan memfasilitasi konflik (GarciaMorales et al., 2018). Untuk meningkatkan kinerja organisasi sektor publik sangat bergantung pada seberapa mampu karyawan dalam hal ini Aparatur Sipil Negara (ASN) memanfaatkan perkembangan teknologi informasi saat ini. Berdasarkan Undang-Undang No. 5 Tahun 2014 yang menyebutkan ASN sebagai perencana, pelaksana, dan pengawas penyelenggaraan tugas umum pemerintah dan pembangunan nasional melalui pelaksanaan kebijakan dan pelayanan publik yang profesional.

Pergeseran paradigma ini mewajibkan seluruh ASN harus dapat menyesuaikan perubahan yang terjadi. Adopsi teknologi mengaharuskan individu untuk menggunakan teknologi sebagai sarana dalam meningkatkan produktivitas (Rubin \& Callaghan, 2019). Namun, kesiapan untuk menerima perubahan ini menjadi tantangan tersendiri bagi organisasi, dimana merubah kebiasaan yang sudah menjadi rutinitas sehari-hari merupakan sesuatu yang sulit. Selain itu, faktor lain seperti usia, lingkungan, dan iklim kerja yang terbangun juga ikut menentukan keberhasilan teknologi informasi dalam meningkatkan kinerja. 
Keberhasilan menyelaraskan organisasi dengan tren teknologi global menjadi sebuah visi baru dimasa depan (Edirisinghe, 2019). Untuk dapat menerapkan teknologi baru, maka dibutuhkan dukungan dari seluruh lapisan organisasi untuk knowledge sharing (Liao, Hsu and To, 2013; Wang and Noe, 2010; Mathuramaytha, 2012; Nooshinfard and Nemati-Anaraki, 2014).

Melalui dukungan knowledge sharing organisasi dapat memenuhi kebutuhan akan informasi dalam proses operasionalnya (El Harbi et al., 2011). Proses interaksi dan komunikasi pertukaran informasi dapat terjadi pada organisasi (Mittal and Dhar, 2015; Wang and Noe, 2010). Identifikasi, akses dan transfer pengetahuan yang bermanfaat untuk menyelesaikan tugas merupakan rakaian dari proses knowledge sharing (Friesl et al., 2011; Wang and Wang, 2012). Sehingga melalui kegiatan knowledge sharing diharapakan dapat berkontribusi dalam meningkatkan kinerja serta mendukung proses adopsi teknologi. Sigala and Chalkiti (2015) peran knowledge sharing juga membantu penerapan teknologi, secara bersamaan meningkatkan kepercayaan kapasitas inovasi organisasi (Chen \& Hou, 2016; Zach \& Hill, 2017). Diharapkan dengan pengadopsian teknologi dan knowledge sharing dapat membantu upaya pemerintah mengwujudkan reformasi birokrasi dan dapat meningkatkan kinerja ASN.

Berdasarkan uraian latar belakang diatas maka penelitian ini memiliki tujuan yaitu, mengetahui, menganalisis, dan menjelaskan pengaruh langsung yang ditunjukkan teknologi informasi dan knowledge sharing terhadap kinerja ASN dan peran knowledge sharing sebagai pemediasi.

\section{TINJAUAN PUSTAKA}

\section{Teknologi Informasi}

Teknologi

informasi didefinisikan sebagai perangkat yang dimanfaat individu untuk menyelesaikan tugas (Maskudi, 2014; Anggraeni, 2020). Melalui proses adaptasi memberikan jaminan antara kesesuaian teknologi dan pengguna sehingga mempermudah dalam mencapai tujuan mereka (Zamani et al., 2020). Berbagai studi telah mengakui hubungan teknologi dengan model bisnis yang berkembang saat ini, dan dikatakan dengan pengembangan teknologi dapat memfasilitasi konsep bisnis baru (Aloini et al., 2021). Perspektif yang terbangun menunjukkan bahwa industri 4.0 diasumsikan sebagai fase industri baru yang mengintegrasikan teknologi sebagai solusi dari bisnis tradisional. Selain itu, teknologi menjadi solusi lintas industry yang paling efektif yang didukung dengan akumulasi modal (Nakano \& Washizu, 2018). Zhang et al. (2020); Santos and Santos (2017)menjelaskan bahwa biaya sebagai pendorong investasi teknologi informasi, dan telah menjadi bagian dari strategi organisasi.

\section{Knowledge Sharing}

Pengetahuan merupakan sumber utama untuk menciptakan keunggulan bersaing yang berkelanjutan (Liao et al., 2013; Casimir et al., 2012; Dysvik et al., 
2015). Wang and Wang (2012) menyatakan bahwa berbagi pengetahuan merupakan proses penerjemahan pengetahuan organisasi menjadi individu dan pengetahuan individu menjadi pengetahuan organisasi. Selain itu, berbagi pengetahuan juga dipahami sebagai proses berbagi gagasan/informasi (Mittal \& Dhar, 2015). Christensen (2007) mendefinisikan berbagi pengetahuan sebagai identifikasi pengetahuan yang ada, selanjutnya digunakan untuk menyelesaikan tugas. Namun, berbagi pengetahuan memiliki tantangan tersendiri dimana karyawan tidak bisa dipaksa melakukannya (Amayah, 2013). Selama ini berbagi pengetahuan dalam organisasi dilakukan melalui knowledge donating dan knowledge collecting (Dysvik et al., 2015; Jain et al., 2015; Mulyana et al., 2015).

\section{Kinerja Karyawan}

Kinerja

karyawan didefinisikan sebagai suatu hal yang telah dilakukan atau belum dilakukan dan seberapa besar kontribusinya terhadap organisasi (Pawirosumarto et al., 2017; Ashforth et al., 2008). Kinerja juga dilihat dari seberapa besar upaya yang dilakukan individu pada pekerjaannya (Stocker et al., 2014; Eriksson et al., 2014). Wulansari et al. (2018) menjelaskan bahwa kinerja karyawan merupakan hasil kerja secara kualitas dan kuantitas yang dapat dicapai oleh karyawan. Namun, untuk dapat menyeimbangkan antara aturan dan prosedur agar dapat memprediksi kinerja karyawan serta disaat bersamaan karyawan juga diberikan kebebasan untuk secara spontan berinovasi untuk beradaptasi dengan tantangan dan situasi (Khoreva \& Wechtler, 2018). Maka kinerja karyawan merupakan satu hal yang penting untuk diukur agar kelangsungan organisasi dapat terjaga.

\section{Kerangka Konsep Penelitian}

Berdasarkan rumusan masalah dan tujuan penelitian maka kerangka konsep penelitian digambarkan sebagai berikut:

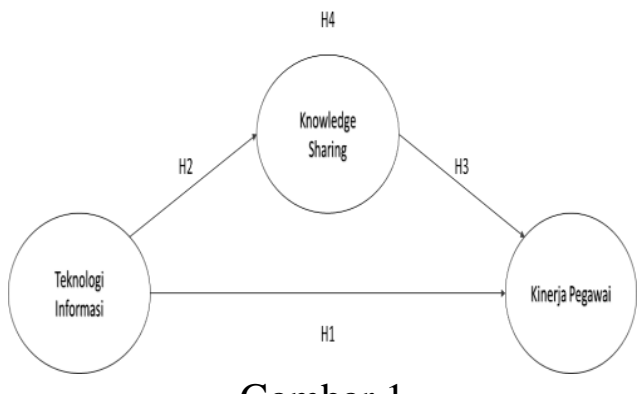

Gambar 1

Kerangka Konsep Penelitian

\section{Hipotesis}

Berdasarkan kerangka konsep yang dibangun dalam penelitian ini maka hipotesis dirumuskan sebagai berikut;
a. Teknologi
informasi berpengaruh signifikan terhadap knowledge sharing.
b. Teknologi informasi berpengaruh signifikan terhadap kinerja pegawai.
c. Knowledge sharing berpengaruh signifikan terhadap kinerja pegawai.
d. Knowledge sharing berperan sebagai pemediasi pengaruh teknologi informasi terhadap kinerja pegawai.




\section{METODE PENELITIAN}

Penelitian ini menggunakan pendekatan kuantitatif yang mengarah pada prinsip-prinsip rasional empirik. Penelitian ini dilakukan pada Dinas Kebudayaan Kabupaten Karangasem, dimana pengumpulan data menggunakan kuesioner. Populasi penelitian ini adalah seluruh pegawai yang bekerja pada Dinas Kebudayaan Kabupaten Karangasem yang berjumlah 49 orang, sehingga metode penentuan sampel menggunakan metode sampel jenuh. Sedangkan untuk teknik analisis data penelitian ini menggunakan analisis jalur (path analysis) dengan SPSS 21. Namun terlebih dahulu dilakukan uji instrumen dengan uji validitas dan reliabilitasnya. Berdasarkan uji yang dilakukan seluruh instrument dinyatakan valid dan reliabel karena memiliki nilai koefisien korelasi (r) lebih tinggi dari 0,3 ( $r>0,3)$, serta nilai Cronbach's Alpha lebih besar dari 0,6 $(\mathrm{a}>0,6)$

\section{HASIL PENELITIAN}

\section{Karakteristik Responden}

Karakteristik responden berdasarkan analisis deskriptif yang dilakukan memberikan informasi bahwa mayoritas responden adalah laki-laki

Tabel 1. Rekapitulasi Analisis Regresi I

Coefficients $^{\mathrm{a}}$

\begin{tabular}{|c|l|r|r|r|r|r|}
\hline \multirow{2}{*}{\multicolumn{2}{|c|}{ Model }} & \multicolumn{2}{|c|}{$\begin{array}{c}\text { Unstandardized } \\
\text { Coefficients }\end{array}$} & $\begin{array}{c}\text { Standardized } \\
\text { Coefficients }\end{array}$ & $\mathrm{t}$ & Sig. \\
\cline { 3 - 7 } \multicolumn{2}{|c|}{} & \multicolumn{1}{|c|}{ B } & $\begin{array}{c}\text { Std. } \\
\text { Error }\end{array}$ & Beta & & \\
\hline 1 & (Constant) & 22,156 & 3,141 & & 7,055 & 0,000 \\
& Teknologi Informasi & 0,335 & 0,093 & 0,465 & 3,603 & 0,001 \\
\hline
\end{tabular}

a. Dependent Variable: Knowledge sharing

Hasil ini dapat dilihat dari nilai besar pengaruh sebesar 0,335 dengan signifikansi 0,001 lebih
$(61,2 \%)$, dengan usia lebih dari 40 Tahun $(53,1 \%)$, dengan status kepegawaian Pegawai Negeri Sipil (PNS) $(59,2 \%)$ dan masa kerja 6 10 tahun $(55,1 \%)$ dan lebih dari 10 tahun $(34,7 \%)$. Hal ini menunjukkan bahwa pegawai yang ditempatkan pada Dinas Kebudayaan Kabupaten Karangasem-Bali merupakkan pegawai yang baru diterima dan dipindahkan dari ke Dinasan lain di lingkungan Pemerintah Daerah Karangasem.

\section{Analisis regresi model I}

Analisis regresi model 1 (satu) digunakan untuk mengetahui kekuatan hubungan dari variabel bebas (Independent) terhadap variabel mediasi (Intervening). Pada analisis regresi model 1 (satu) persamaan strukturalnya adalah: Knowledge sharing $=$ b1 teknologi informasi + e1

Berdasarkan pada hasil analisis yang dilakukan dapat diketahui bahwa teknologi informasi berpengaruh positif dan signifikan terhadap knowledge sharing. 
hipotesis yang disajikan dalam bagian ini.

\section{Analisis Regresi Model 2}

Analisis regresi model 2 (dua) digunakan untuk mengetahui kekuatan hubungan dari variabel bebas (independent) terhadap variabel terikat (dependent). Pada analisis regresi model 2 persamaan strukturalnya adalah: Kinerja pegawai $=$ b1 Teknologi Informasi $+\mathrm{b} 2$ Knowledge sharing + e2

Tabel 2 Rekapitulasi Analisis Regresi II

Coefficients $^{\mathrm{a}}$

\begin{tabular}{|c|c|c|c|c|c|c|}
\hline \multirow{2}{*}{\multicolumn{2}{|c|}{ Model }} & \multicolumn{2}{|c|}{$\begin{array}{l}\text { Unstandardized } \\
\text { Coefficients }\end{array}$} & $\begin{array}{l}\text { Standardized } \\
\text { Coefficients }\end{array}$ & \multirow[t]{2}{*}{$\mathrm{t}$} & \multirow[t]{2}{*}{ Sig. } \\
\hline & & $\mathrm{B}$ & Std. Error & Beta & & \\
\hline \multirow{3}{*}{1} & (Constant) & 6,648 & 2,933 & & 2,267 & 0,028 \\
\hline & Teknologi Informasi & 0,064 & 0,068 & 0,1 & 0,939 & 0,353 \\
\hline & Knowledge sharing & 0,636 & 0,095 & 0,716 & 6,703 & 0,000 \\
\hline
\end{tabular}

a. Dependent Variable: Kinerja

Berdasarkan pada hasil analisis yang dilakukan dapat diketahui bahwa teknologi informasi berpengaruh positif tidak signifikan terhadap kinerja pegawai. Hasil ini dapat dilihat dari nilai besar pengaruh sebesar 0,064 dengan signifikansi 0,353 lebih dari 0,05 sehingga $\mathrm{H} 2$ tidak terdukung. Namun dari hasil analisis yang dilakukan dapat diketahui bahwa knowledge sharing berpengaruh positif dan signifikan terhadap kinerja. Hasil ini dapat dilihat dari nilai besar pengaruh sebesar 0,636 dengan signifikansi 0,000 lebih kecil dari 0,05 sehingga $\mathrm{H} 3$ terdukung

Tabel 3 Uji Mediasi (Sobel Test)

\begin{tabular}{l|l|l|l|}
$\begin{array}{l}\text { Teknologi Informasi } \rightarrow \\
\text { Knowledge Sharing } \rightarrow \\
\text { Kinerja Pegawai }\end{array}$ & $\begin{array}{l}\left.0,335 \cdot 0,636 / \sqrt{\left(0,636^{2}\right.} \cdot 0,093^{2}\right)+ \\
\left(0,335^{2} \cdot 0,095^{2}\right)=3,1721\end{array}$ & 1,96 & Terdukung \\
\hline
\end{tabular}

\section{Uji mediasi dilakukan} dengan Sobel Test, hasil menunjukkan knowledge sharing terbukti sebagai pemediasi pengaruh teknologi informasi terhadap kinerja pegawai dengan nilai Sobel test statistic 3,1721 lebih besar dari 1,96 dengan tingkat signifikansi (5\%) sehingga H4 terdukung.

\section{Pembahasan}

Dari hasil analisis menunjukkan bahwa teknologi informasi berpengaruh positif signifikan terhadap knowledge sharing. Hasil ini menunjukkan bahwa semakin tinggi penerapan teknologi informasi, maka semakin tinggi kegiatan berbagi pengetahuan yang dilakukan pegawai pada Dinas Kebudayaan Kabupaten Karangasem, hasil ini mendukung temuan (Kim and Lee, 2006; Davison, Ou and Martinsons, 2013; Arpaci and Balotlu, 2016). Temuan ini juga memberikan kontribusi bahwa dengan penerapan teknologi informasi akan lebih meningkatkan keingingan 
karyawan untuk melakukan knowledge sharing. Selain itu, dengan meningkatnya kegiatan berbagi pengetahuan membantu para karyawan dalam melakukan proses kerjasama yang bermanfaat dalam peningkatan pengelolaan organisasi.

Namun, teknologi informasi berpengaruh positif tidak signifikan terhadap kinerja pegawai pada Dinas Kebudayaan Kabupaten Karangasem. Hasil ini menjelaskan bahwa semakin meningkatnya teknologi informasi belum mampu meningkatkan kinerja pegawai. Hal ini tidak lepas dari kebijakan yang berlaku, dimana kinerja pegawai sudah ditetapkan sesuai dengan target capaian setiap pegawai, Sehingga dengan atau tanpa dibantu teknologi informasi kinerja karyawan harus tercapai. Sehingga temuan ini berbeda dengan kajian sebelumnya (Huang et al., 2015; Astika and Dwirandra, 2020; Hendrato et al., 2021).

\section{Temuan} selanjutnya menunjukkan knowledge sharing berpengaruh positif signifikan terhadap kinerja pegawai. Hasil ini menjelaskan bahwa semakin tinggi praktik knowledge sharing semakin meningkat kinerja pegawai pada Dinas Kebudayaan Kabupaten Karangasem. Hasil ini sejalan dengan temuan penelitian sebelumnya (Giri et al., 2011; Kuzu and Özilhan, 2014; Aksoy et al., 2016; Sajid, 2016). Selain menunjukkan pengaruh langsung, knowledge sharing juga terbukti sebagai mediasi penuh (fully mediation) pengaruh teknologi informasi terhadap kinerja pegawai pada Dinas Kebudayaan Kabupaten Karangasem. Hal ini menjelaskan bahwa praktik berbagi pengetahuan dapat membantu organisasi dalam meningkatkan kinerja karyawannya. Berbagai temuan (Abhishek Srivastava et al., 2006; Hsu, 2008; Tabrizi, 2014; Zhu and Chen, 2014; Mittal and Dhar, 2015; Masa'deh et al., 2016) telah menjelaskan bahwa berbagi pengetahuan merupakan hal yang sangat penting dilakukan sehingga organisasi dapat mengadopsi halhal baru termasuk teknologi.

\section{PENUTUP}

\section{Simpulan}

Berdasarkan hasil dan pembahasan, maka dapat ditarik beberapa kesimpulan sebagai berikut:

1. Teknologi Informasi berpengaruh positif dan signifikan terhadap knowledge sharing. Hal ini menunjukkan bahwa semakin tinggi penerapan teknologi informasi semakin tinggi knowledge sharing di Dinas Kebudayaan Kabupaten Karangasem.

2. Teknologi Informasi berpengaruh positif tidak siginifikan terhadap kinerja pegawai. Hal ini menjelaskan bahwa semakin tinggi penerapan teknologi informasi belum mampu meningkatkan kinerja pegawai di Dinas Kebudayaan Kabupaten Karangasem.

3. Knowledge sharing berpengaruh positif dan signifikan terhadap kinerja pegawai. Hal ini 
menunjukkan semakin tinggi perilaku knowledge sharing semakin tinggi kinerja pegawai di Dinas Kebudayaan Kabupaten Karangasem.

4. Knowledge sharing terbukti sebagai variabel pemediasi teknologi informasi terhadap kinerja pegawai. Hasil ini menunjukkan bahwa untuk meningkatkan penerapan teknologi informasi dibutuhkan peran knowledge sharing untuk meningkatkan kinerja pegawai di Dinas Kebudayaan Kabupaten Karangasem

\section{Saran}

Sebagai upaya meningkatkan kinerja pegawai Dinas Kebudayaan Kabupaten Karangasem diantaranya meningkatkan kegiatan berbagi pengetahuan yang meliputi kegiatan mengumpulkan dan mendonasikan pengetahuan. Teknologi informasi menunjukkan pengaruh tidak signifikan terhadap kinerja, sehingga instansi harus meningkatkan pemahaman tinggi tentang teknologi informasi, karena saat ini semua kegiatan sudah berbasis e-government dan dimasa depan semua kegiatan pemerintahan akan berbasis teknologi. Untuk peneliti selanjutnya agar dapat lebih menyempurnakan penelitian ini dengan menggunakan beberapa faktor lainnya yang dapat mempengaruhi kinerja pegawai.

\section{DAFTAR PUSTAKA}

Abhishek Srivastava, Kathryn M Bartol, \& Edwin a Locke. (2006). Epowering Leadership in Management Teams: Effects on Knowledge Sharing, Efficacy, and Performance. Academy of Management Journal, $\quad 49(6), \quad 1239$. https://doi.org/10.5465/AMJ.20 06.23478718

Aksoy, Y., Ayranci, E., \& Gozukara, E. (2016). A Research on the Relationship between Knowledge Sharing and Employee Performance: The Moderating Role of Unethical Behaviors in Organizational Level. European Scientific Journal, ESJ, 12(4), 335. https://doi.org/10.19044/esj.20 16.v12n4p335

Aloini, D., Latronico, L., \& Pellegrini, L. (2021). The impact of digital technologies on business models. Insights from the space industry. Measuring Business Excellence. https://doi.org/10.1108/MBE12-2020-0161

Amayah, A. T. (2013). Determinants of knowledge sharing in a public sector organization. Journal of Knowledge Management, 17(3), 454-471. https://doi.org/10.1108/JKM11-2012-0369

Anderson, C. R. B. B. (2010). Employee's green behavior for environmental sustainability: a case of banking sector in Pakistan. World Journal of Science, Technology and Sustainable Development, 12(3), 194-205.

Anggraeni, A. (2020). Executive role in the use of information technology in public organisations. Journal of Business Management and 
Accounting, 4(1), 17-32.

Arpaci, I., \& Balotlu, M. (2016). The impact of cultural collectivism on knowledge sharing among information technology majoring undergraduates. Computers in Human Behavior, 56 , $65-71$. https://doi.org/10.1016/j.chb.20 15.11.031

Ashforth, B. E., Harrison, S. H., \& Corley, K. G. (2008). Identification in organizations: An examination of four fundamental questions. Journal of Management, 34(3), 325374.

https://doi.org/10.1177/014920 6308316059

Astika, I. B. P., \& Dwirandra, A. (2020). Information technology duty, satisfaction and ais effectiveness moderate effect of benefits of informs technology on employee performance. International Research Journal of Management, IT and Social Sciences, 7(6), 9-20. https://doi.org/10.21744/irjmis. v7n6.996

Bonacina Roldan, L., Hansen, P. B., \& Garcia-Perez-de-Lema, D. (2018). The relationship between favorable conditions for innovation in technology parks, the innovation produced, and companies' performance. Innovation \& Management Review, 15(3), 286-302. https://doi.org/10.1108/inmr05-2018-0027

Casimir, G., Lee, K., \& Loon, M. (2012). Knowledge sharing: Influences of trust, commitment and cost. Journal of Knowledge Management, 16(5), 740-753. https://doi.org/10.1108/136732 71211262781

Chen, A. S. Y., \& Hou, Y. H. (2016). The effects of ethical leadership, voice behavior and climates for innovation on creativity: A moderated mediation examination. Leadership Quarterly, 27(1), 113.

https://doi.org/10.1016/j.leaqua .2015 .10 .007

Christensen, P. H. (2007). Knowledge sharing: Moving away from the obsession with best practices. Journal of Knowledge Management, 11(1), 36-47. https://doi.org/10.1108/136732 70710728222

Davison, R. M., Ou, C. X. J., \& Martinsons, M. G. (2013). Information technology to support informal knowledge sharing. Information Systems Journal, 23(1), 89-109. https://doi.org/10.1111/j.13652575.2012.00400.x

Dysvik, A., Buch, R., \& Kuvaas, B. (2015). Knowledge donating and knowledge collecting. Leadership \& Organization Development Journal, 36(1), 35-53.

https://doi.org/10.1108/LODJ11-2012-0145

Edirisinghe, R. (2019). Digital skin of the construction site: Smart sensor technologies towards the future smart construction site. Engineering, Construction and Architectural Management, 26(2), 184-223. https://doi.org/10.1108/ECAM04-2017-0066

El-Kassar, A. N., \& Singh, S. K. (2019). Green innovation and 
organizational performance: The influence of big data and the moderating role of management commitment and HR practices. Technological Forecasting and Social Change, 144(December), 483498.

https://doi.org/10.1016/j.techfo re.2017.12.016

El Harbi, S., Anderson, A. R., \& Amamou, M. (2011). Knowledge sharing processes in Tunisian small ICT firms. Library Review, 60(1), 24-36. https://doi.org/10.1108/002425 31111100559

Eriksson, T., Qin, Z., \& Wang, W. (2014). Firm-level innovation activity, employee turnover and HRM practices - Evidence from Chinese firms. China Economic Review, 30, 583-597. https://doi.org/10.1016/j.chieco .2014 .02 .005

Friesl, M., Sackmann, S. A., \& Kremser, S. (2011). Knowledge sharing in new organizational entities: The impact of hierarchy, organizational context, micro-politics and suspicion. Cross Cultural Management: An International Journal, 18(1), 71-86. https://doi.org/https://doi.org/1 $0.1108 / 13527601111104304$

Garcia-Morales, V. J., Martín-Rojas, R., \& Lardón-López, M. E. (2018). Influence of social media technologies on organizational performance through knowledge and innovation. Baltic Journal of Management, 13(3), 345-367. https://doi.org/10.1108/BJM04-2017-0123
García-Sánchez, Encarnacion, García-Morales, V. J., \& Martín-Rojas, R. (2018). Analysis of the influence of the environment, stakeholder integration capability, absorptive capacity, and technological skills on organizational performance through corporate entrepreneurship. International Entrepreneurship and Management Journal, 14(2), 345-377.

https://doi.org/10.1007/s11365017-0436-9

García-Sánchez, Encarnación, Guerrero-Villegas, J., \& Aguilera-Caracuel, J. (2018). How do technological skills improve reverse logistics? The moderating role of top management support in information technology use and innovativeness. Sustainability (Switzerland), 11(1), 1-17. https://doi.org/10.3390/su1101 0058

Giri, E. E., Nimran, U., Hamid, D., Musadieq, A., \& Al Musadieq, M. (2011). The Effect of Organizational Culture and Organizational Commitment to Job Involvement, Knowledge Sharing, and Employee Performance: A Study on Regional Telecommunications Employees of PT Telkom, East Nusa Tenggara Province, Indonesia. International Journal of Management and Administrative Sciences, 3(04), 20-33. www.ijmas.org

Hendrato, M. L., Subyantoro, A., \& Wisnalmawati. (2021). The Effect of Organizational 
Culture and Information Technology on Employee Performance with Employee Satisfaction as a Mediator in The Electronic Court System (E-Court) in District Court of Sleman, Yogyakarta. Proceedings of the 4th International Conference on Sustainable Innovation 2020Accounting and Management (ICoSIAMS 2020), 176(ICoSIAMS 2020), 242246.

https://doi.org/10.2991/aer.k.21 0121.033

Hsu, H. Y., Liu, F. H., Tsou, H. T., \& Chen, L. J. (2019). Openness of technology adoption, top management support and service innovation: a social innovation perspective. Journal of Business and Industrial Marketing, 34(3), 575-590. https://doi.org/10.1108/JBIM03-2017-0068

Hsu, I. C. (2008). Knowledge sharing practices as a facilitating factor for improving organizational performance through human capital: A preliminary test. Expert Systems with Applications, 35(3), 13161326.

https://doi.org/10.1016/j.eswa. 2007.08.012

Huang, S. Y., Lee, C. H., Chiu, A. A., \& Yen, D. C. (2015). How business process reengineering affects information technology investment and employee performance under different performance measurement. Information Systems Frontiers, 17(5), 1133-1144. https://doi.org/10.1007/s10796-
014-9487-4

Jain, K. K., Sandhu, M. S., \& Goh, S. K. (2015). Organizational climate, trust and knowledge sharing: insights from Malaysia. Journal of Asia Business Studies, 9(1), 54-77. https://doi.org/10.1108/JABS07-2013-0040

Khoreva, V., \& Wechtler, H. (2018). HR practices and employee performance: the mediating role of well-being. Employee Relations, 40(2), 227-243. https://doi.org/10.1108/ER-082017-0191

Kim, S., \& Lee, H. (2006). The Impact of Organizational Context and Information Technology on Employee Knowledge-Sharing

Capabilities.

Public Administration Review, 66(3), 370-385.

https://doi.org/10.1111/j.15406210.2006.00595.x

Kuzu, Ö. H., \& Özilhan, D. (2014). The Effect of Employee Relationships and Knowledge Sharing on Employees' Performance: An Empirical Research on Service Industry. Procedia - Social and Behavioral Sciences, 109, 1370-1374.

https://doi.org/10.1016/j.sbspro .2013.12.639

Lee, J., Lee, H., Park, J.-G., Ochara, N. M., Kandiri, J., \& Johnson, R. (2014). Information Technology \& People Exploring the impact of empowering leadership on knowledge sharing, absorptive capacity and team performance in IT service"Influence 
processes of implementation effectiveness in challenged information technology projects in. Information Technology \& People, 27(3), 366-386.

https://doi.org/10.1108/ITP-102012-0115

Lee, J. S., Park, J. H., \& Bae, Z. T. (2017). The effects of licensingin on innovative performance in different technological regimes. Research Policy, 46(2), 485496.

https://doi.org/10.1016/j.respol. 2016.12.002

Liao, C., Hsu, F. C., \& To, P. L. (2013). Exploring knowledge sharing in virtual communities. Online Information Review, 37(6), 891-909. https://doi.org/10.1108/OIR11-2012-0196

Masa'deh, R., Obeidat, B. Y., \& Tarhini, A. (2016). A Jordanian empirical study of the associations among transformational leadership, transactional leadership, knowledge sharing, job performance, and firm performance: A structural equation modelling approach. Journal of Management Development, 35(5), 681-705. https://doi.org/10.1108/JMD09-2015-0134

Maskudi. (2014). the Mediating Effect of High Performance Work Systems in the Organizarional Culture and Information Technology Toward Managerial Performance: Studi at Coorperative in Semarang City, Provice of Central Java,
Indonesia). Jurnal Ekonomi Dan Bisnis, 9(18). https://doi.org/http://dx.doi.org/ 10.31942/akses.v9i18.1375

Mathuramaytha,

C.

(2012). Developing KnowledgeSharing Capabilities Influence Innovation Capabilities in Organizations-a Theoretical Model. International Conference on Education and Management Innovation IPEDR, 30, 285-291.

Mittal, S., \& Dhar, R. L. (2015). Transformational leadership and employee creativity: Mediating role of creative selfefficacy and moderating role of knowledge sharing. Management Decision, 53(5), 894-910.

https://doi.org/10.1108/MD07-2014-0464

Mulyana, Assegaff, M., \& Wasitowati. (2015). Pengaruh Knowledge Donating dan Knowledge Collecting terhadap Innovation Capability Kasus Pengembangan UKM Batik di Provinsi Jawa TengahIndonesia. Jurnal Manajemen Teknologi, 14(3), 246-264. https://doi.org/10.12695/jmt.20 15.14.3.2

Nakano, S., \& Washizu, A. (2018). Induced effects of smart food/agri-systems in Japan: Towards a structural analysis of information technology. Telecommunications Policy, 42(10), 824-835. https://doi.org/10.1016/j.telpol. 2018.08.001

Nooshinfard, F., \& Nemati-Anaraki, L. (2014). Success factors of inter-organizational knowledge 
sharing: A proposed framework. Electronic Library, $32(2)$, 239-261. https://doi.org/10.1108/EL-022012-0023

Pawirosumarto, S., Sarjana, P. K., \& Gunawan, R. (2017). The effect of work environment, leadership style, and organizational culture towards job satisfaction and its implication towards employee performance in Parador hotels and resorts, Indonesia. International Journal of Law and Management, 59(6), 13371358.

https://doi.org/10.1108/IJLMA -10-2016-0085

Rubin, A., \& Callaghan, C. W. (2019). Entrepreneurial orientation, technological propensity and academic research productivity. Heliyon, 5(8), e02328. https://doi.org/10.1016/j.heliyo n.2019.e02328

Sajid, M. (2016). The Impact of Job Satisfaction and Knowledge Sharing on Employee Performance. Journal of Resources Development and Management, 21(1992), 16-23.

Santos, L. C., \& Santos, C. D. dos. (2017). A study on the impact of non-operational mechanisms on the effectiveness of public information technology governance. Revista de Administração, 52(3), 256-267. https://doi.org/10.1016/j.rausp. 2017.05.005

Sigala, M., \& Chalkiti, K. (2015). Knowledge management, social media and employee creativity. International Journal of
Hospitality Management, 45, 44-58.

https://doi.org/10.1016/j.ijhm.2 014.11 .003

Stocker, D., Jacobshagen, N., Krings, R., Pfister, I. B., \& Semmer, N. K. (2014). Appreciative leadership and employee wellbeing in everyday working life. Zeitschrift Fur Personalforschung, 28(1-2), 73-95.

https://doi.org/10.1688/ZfP2014-01-Stocker

Tabrizi, N. M. (2014). Models for describing incident knowledge sharing practices: The case study of UK hospital. Proceedings of the European Conference on Knowledge Management, ECKM, 3, 12911300.

Wang, S., \& Noe, R. A. (2010). Knowledge sharing: A review and directions for future research. Human Resource Management Review, 20(2), 115-131.

https://doi.org/10.1016/j.hrmr.2 009.10.001

Wang, Z., \& Wang, N. (2012). Knowledge sharing, innovation and firm performance. Expert Systems with Applications, 39(10), 8899-8908. https://doi.org/10.1016/j.eswa. 2012.02.017

Wulansari, N. A., Witiastuti, R. S., \& Ridloah, S. (2018). Employee Performance Measurement Development Based on Green HRM Indicators. KnE Social Sciences, 3(10), 1179. https://doi.org/10.18502/kss.v3 i10.3201 
Zach, F. J., \& Hill, T. L. (2017). Network, knowledge and relationship impacts on innovation in tourism destinations. Tourism Management, 62, 196-207. https://doi.org/10.1016/j.tourm an.2017.04.001

Zamani, E. D., Pouloudi, N., Giaglis, G. M., \& Wareham, J. (2020). Appropriating Information Technology Artefacts through Trial and Error: The Case of the Tablet. Information Systems Frontiers.

https://doi.org/10.1007/s10796020-10067-8

Zhang, X., Pieter, D., Donk, V., \& Jayaram, J. (2020). A multitheory perspective on enablers of inter-organizational information and communication technology: A comparison of China and the Netherlands. International Journal of Information Management, 54(June), 102191.

https://doi.org/10.1016/j.ijinfo mgt.2020.102191

Zhu, C., \& Chen, X. (2014). High Performance Work Systems and Employee Creativity: The Mediating Effect of Knowledge Sharing. Frontiers of Business Research in China, 8(3), 367387.

https://doi.org/https://doi.org/1 0.3868/s070-003-014-0017-3 